\title{
Experimental Study on the Shear Transfer of Composite Pre-Slabs with H.S.C Top Layer Using Different Shear Dowels Percentage
}

\author{
M.M El-Hawary \\ Teaching Assistant \\ Construction Engineering Department \\ Misr University for Science \&Technology
}

\author{
W. Zaki \\ Assistant Professor \\ Civil Engineering Department \\ Beni-Suef University
}

\author{
M. Rabie \\ Professor of Structure \\ Engineering Department \\ Cairo University
}

\begin{abstract}
The aim of research is to study the influnce of concrete strength , case of loading, percentage and distribution of shear connectors on shear transfer of one way composite preslabs composed of two concrete layers with different compressive strength the first layer (normal strength concrete and the second layer high strength concrete). An expermental program has been performed to investigate the research point,where fourteen specimens were supported on two edge supports to represent the case of one way simply supported slab and tested under the case of uniformly distributed loads, one concentrated line load and two concentrated line loads. Specimens were grouped into four groups to study the influence of dowel distribution, percentage and surface condition between two slab layers. It was concluded that Increasing of shear connectors ratio with uniform distribution leds to increasing in ultimate load and shear strength, decrease in dowels' strain, decrease in horizontal slippage in case of roughening the interface surface and Increasing in ductility for pre-slabs.
\end{abstract}

Key words- Shear transfer- High strength concreteInterface roughness- Dowels

\section{INTRODUCTION}

The problem of shear transfer in concrete structures arises when shearing forces are transmitted across a definite plane. Typical situations can be found in the design, such as corbels, non-monolithic joints in concrete and composite members where concrete is cast in place over pre-cast elements. The composite interface presents a potential weakness; they must be designed to have, at least, the same shear capacity of the adjoining parts. To achieve the composite action between old and new part, different types of shear connection between the two concrete surfaces may be used, such as rough surface connection, steel doweled shear connection.

El-Behairy, Sh., and Abu El-Enin [1] had carried out a test on concrete slabs cast at different times. The effect of surface condition was studied and they found that specimens with roughened interface gave the best results. Also, slabs with smooth and troweled interface with steel dowels of area less than $0.15 \%$, did not reach the monolithic stage.

Zaky, W [2] had tested six composites one way simply supported pre-slabs $106 \times 80 \times 10 \mathrm{~cm}$, the results showed that, the design of the tested specimens successes to change the mode of failure from flexure failure to shear failure also, the changing of loading type from uniformly distributed loads to concentrated one-line load led to achieve the ultimate shear strength.

Rabie, M [3] had performed a test on four composites two way-simply supported pre-slabs $2 \times 2 \times 0.1 \mathrm{~m}$ under the action of distributed load, the results showed that the ultimate load for the composite slab with rough interface only was about $87 \%$ of that of monolithic one, and also a slightly higher value of both deflection and concrete compressive stress was measured up to the complete separation of the two layers. Also, pre-slabs with distributed dowels $1 \phi 8$ every $40 \mathrm{~cm}$ gives higher ultimate load than pre-slab of concentrated dowels over the outside perimeter of width (0.25 span) with the same area. While the use of concentrated dowels decreased both deflection and stress in dowels until the separation of the two layers in the interior zones which led to sudden increase in both deflection and dowels stress.

Abou El-Maaty, M.A [4] had been discussed the behavior of R.C pre-cast corrugated deck slab. The slab consists of a precast corrugated R.C layer and an in-situ lightly R.C topping layer. The researcher suggested a model to predict the shear transfer of initially cracked concrete taking into account the compressive stresses level acting normal to the shear plane ElZanaty, A. [5].

Hussien, I.A [6] The composite interface between steel and concrete or between two concrete layers is one of the difficulties in constructing an analytical model for composite reinforced concrete members. More than one model has been proposed. The author used the linkage elements with 3rd degree polynomial based on experimental test on push-off specimens mad by previous works.

Abdel-Hay, A.SH [7] studied that the effect of interface position and percentage of shear connectors on the behavior of one-way composite pre-slabs. The experimental program contains testing of nine one way simply supported pre-slabs and one reference monolithic slab. The main conclusion was that; the maximum ultimate load obtained for pre-slab with bottom layer of thickness higher than top layer was affected by increasing the percentage of dowels, while in other cases; the ultimate load was less affected by this increase. Also, in case of higher depth of first layer we must use a higher percent of dowels not less than $0.15 \%$, but $0.1 \%$ was enough in other cases. 


\section{RESEARCH PARAMETERS}

The objective of the experimental program is to study the influence of the dowel distribution, percentage and surface condition between two slab layers on the shear transfer of oneway composite pre-slabs.

\section{EXPERMENTAL PROGRAM}

Experimental program was carried out on six monolithic slabs and eight composite pre-slabs; Both the monolithic and preslabs had been supported on two edge supports to represent the case of one way simply supported slab. Firstly, the monolithic slab consists of one concrete layer with dimensions $1060 * 800 * 100 \mathrm{~mm}$ with main bottom reinforcement of $10 \Phi 12 \mathrm{~mm}$ and secondary reinforcement of $6 \Phi 6 \mathrm{~mm}$ as shown in Figure 1. Secondly the composite slab consists of two concrete layers; the first layer was slab with dimensions $1060 * 800 * 50 \mathrm{~mm}$ with main bottom reinforcement of $10 \Phi 12$ $\mathrm{mm}$, secondary reinforcement of $6 \Phi 6 \mathrm{~mm}$ and its $\mathrm{Fcu}=35$ $\mathrm{N} / \mathrm{mm}^{2}$. The second layer had the same dimensions as the first layer $1060 * 800 * 50 \mathrm{~mm}$ without reinforcement and its $\mathrm{Fcu}=60$ $\mathrm{N} / \mathrm{mm}^{2}$ as shown in the figure 2 .

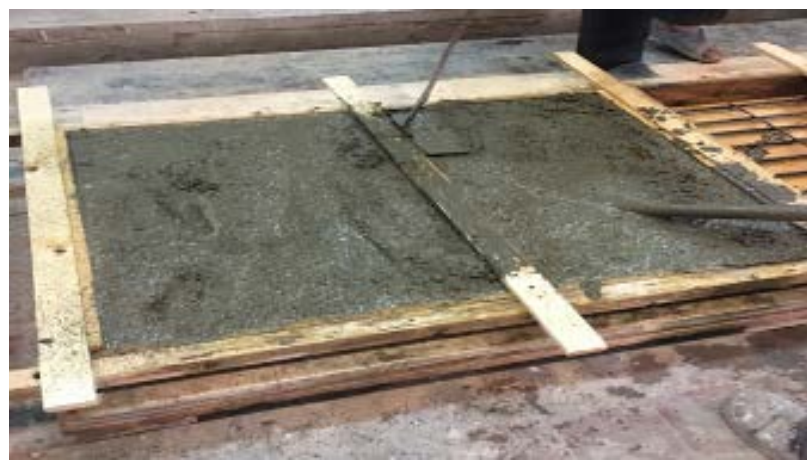

Figure 1: Monolithic slab specimen

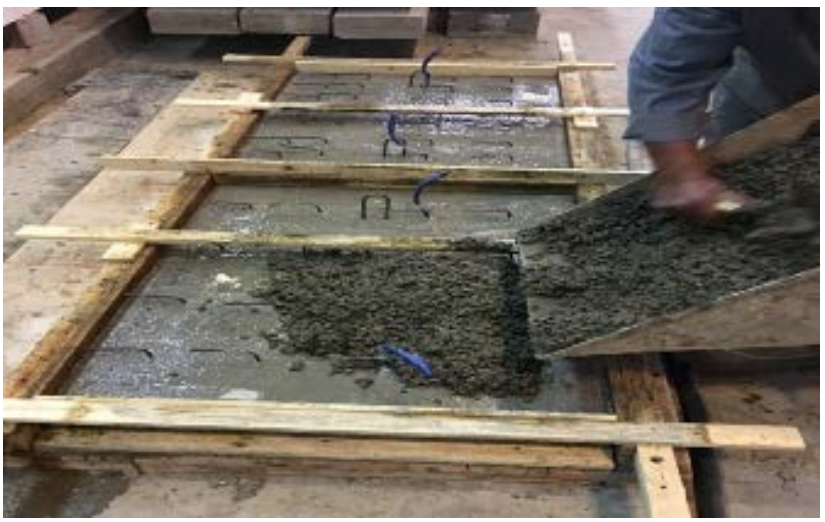

Figure 2: Pre-slab specimen

All the tested specimens were of $100 \mathrm{~mm}$ thickness and are classified as follows:

R-N-U: Monolithic slab tested under the effect of uniformly distributed loads, with $\mathrm{Fcu}=35 \mathrm{~N} / \mathrm{mm}^{2}$.

R-N-O: Monolithic slab tested under the effect of one-line loads act at a distance of $20 \%$ of the span from one edge, with $\mathrm{Fcu}=35 \mathrm{~N} / \mathrm{mm}^{2}$.

R-N-T: Monolithic slab tested under the effect of two-line loads act at a distance of $20 \%$ of the span from the two edges, with $\mathrm{Fcu}=35 \mathrm{~N} / \mathrm{mm}^{2}$.
R-H-U: Monolithic slab tested under the effect of uniformly distributed loads, with $\mathrm{Fcu}=60 \mathrm{~N} / \mathrm{mm}^{2}$.

R-H-O: Monolithic slab tested under the effect of one-line loads act at a distance of $20 \%$ of the span from one edges, with $\mathrm{Fcu}=60 \mathrm{~N} / \mathrm{mm}^{2}$.

R-H-T: Monolithic slab tested under the effect of two-line loads act at a distance of $20 \%$ of the span from the two edges, with $\mathrm{Fcu}=60 \mathrm{~N} / \mathrm{mm}^{2}$.

$0.1 \%-\mathrm{U}$ : composite slab tested under the effect of uniformly distributed load had uniform dowels distribution of ratio equals to $0.1 \%$.

0.1\%-O: composite slab tested under the effect of one-line load acts at a distance of $20 \%$ of the span from one edge and had uniform dowels distribution of ratio equals to $0.1 \%$.

$0.1 \%-\mathrm{O}-\mathrm{R}$ : composite slab tested under the effect of one-line load acts at a distance of $20 \%$ of the span from one edge, had uniform dowels distribution of ratio equals to $0.1 \%$ and had only roughening on the interface area between the two concrete layers.

$0.1 \%-\mathrm{T}$ : composite slab tested under the effect of two-line load acts at a distance of $20 \%$ of the span from the two edges, dowels with ratio equals to $0.1 \%$ and $50 \%$ of dowels area put in each one quarter of the outside span while the middle part of the span was without any dowels.

$0.06 \%-U$ : composite slab tested under the effect of uniformly distributed load had uniform dowels distribution of ratio equals to $0.06 \%$.

0.06\%-O: composite slab tested under the effect of one-line load acts at a distance of $20 \%$ of the span from one edge and had uniform dowels distribution of ratio equals to $0.06 \%$.

$0.06 \%-\mathrm{O}-\mathrm{R}$ : composite slab tested under the effect of one-line load acts at a distance of $20 \%$ of the span from one edge, had uniform dowels distribution of ratio equals to $0.06 \%$ and had only roughening on the interface area between the two concrete layers.

0.06\%-T: composite slab tested under the effect of two-line load acts at a distance of $20 \%$ of the span from the two edges, dowels with ratio equals to $0.06 \%$ and $50 \%$ of dowels area put in each one quarter of the outside span while the middle part of the span was without any dowels.

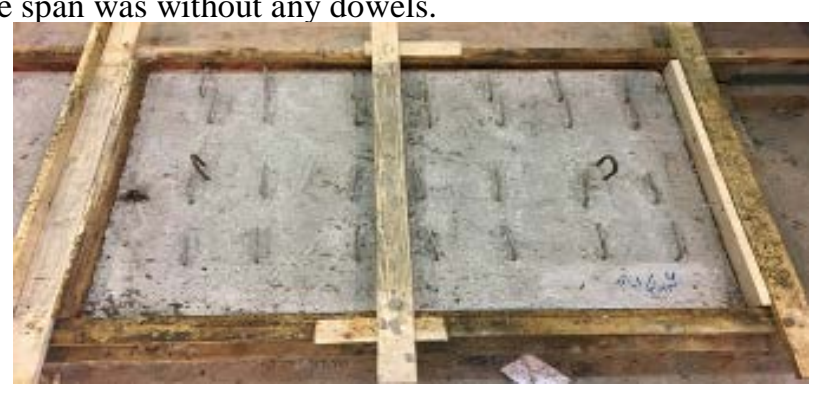

Figure 3: uniform dowels $0.1 \%$ distribution

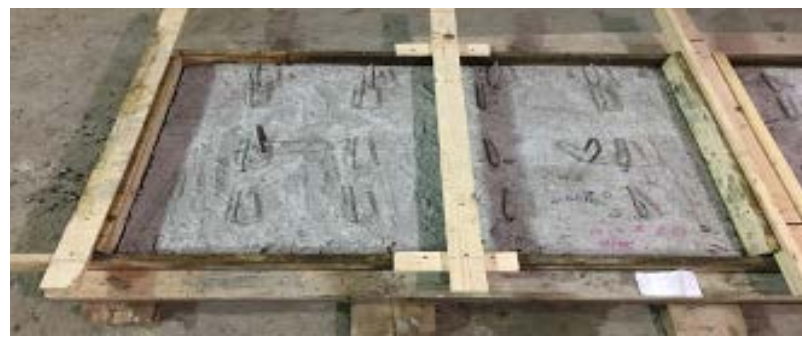

Figure 4: uniform dowels $0.06 \%$ distribution 


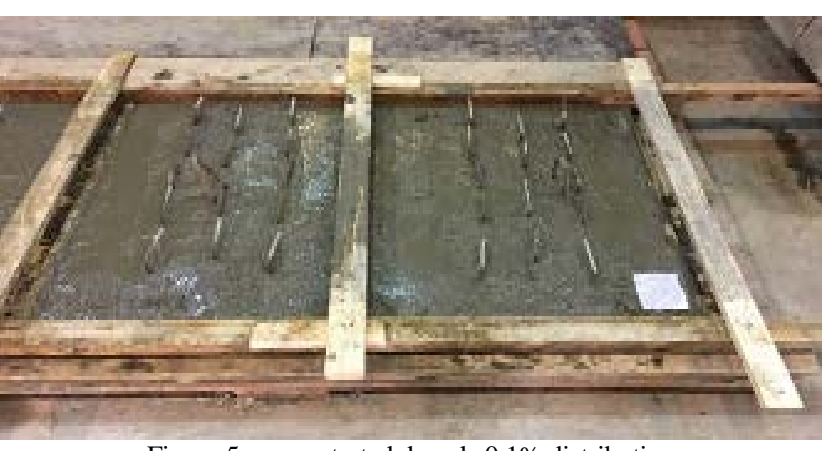

Figure 5: concentrated dowels $0.1 \%$ distribution

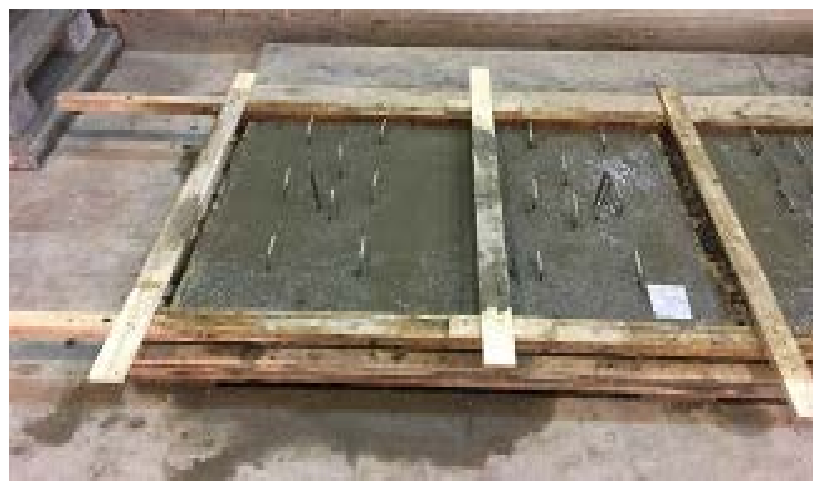

Figure 6: concentrated dowels $0.06 \%$ distribution

\section{TEST PROCEDURES AND INSTRUMENTATION}

The specimens were tested under the effect of tree types of loading; the first case of loading was the effect of uniform distributed load through a whiffed tree arrangement, the second case of loading was the effect of one-line load while the third case of loading was the effect of two-line loads.

All slabs were supported on two edge supports to represent the case of one way simply supported slab and the loads were applied by a hydraulic jack, the loading was increased by an increment equal to 1 ton. The load was kept constant between each two successive increments to detect the cracks and also to measure dowels strain, concrete tensile strain, vertical deflection and slippage.

The preloading due to the own weight of specimens, hydraulic jack, loadcell and steel joists had been taken into consideration in the analyses. The different load arrangements are shown in figure 7 through figure 8 .

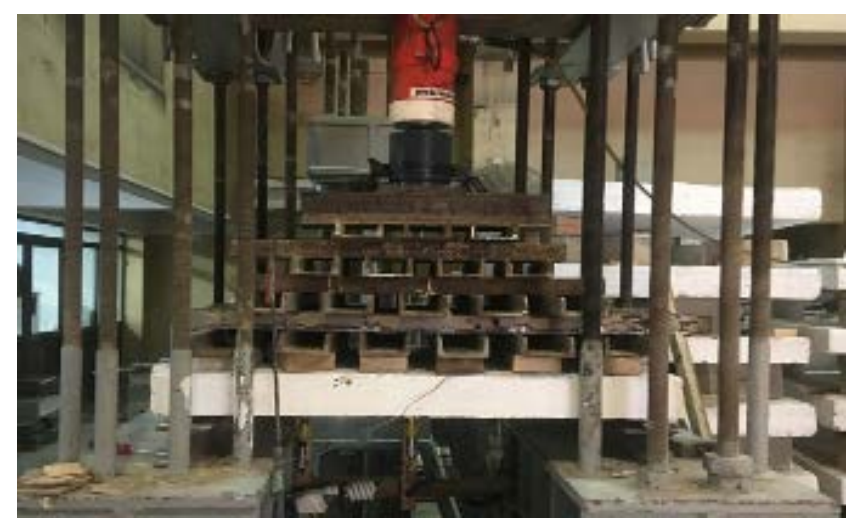

Figure 7: Uniformly distributed load

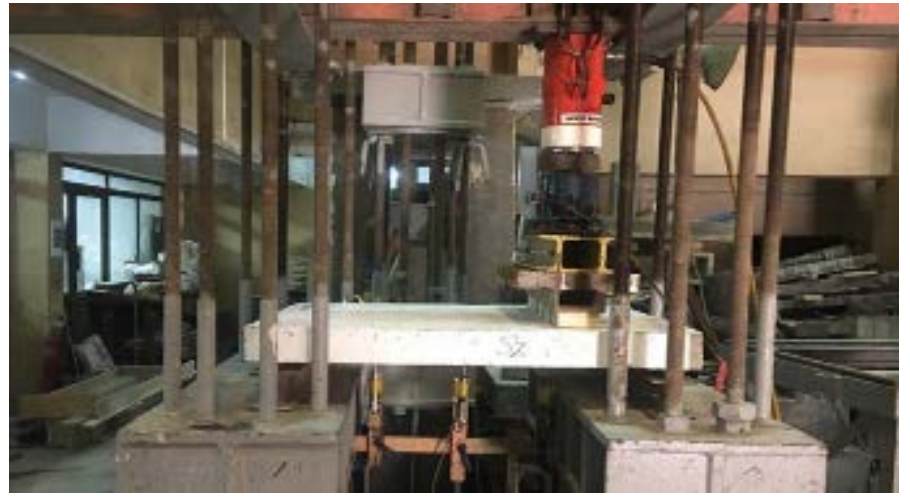

Figure 8: One-line load

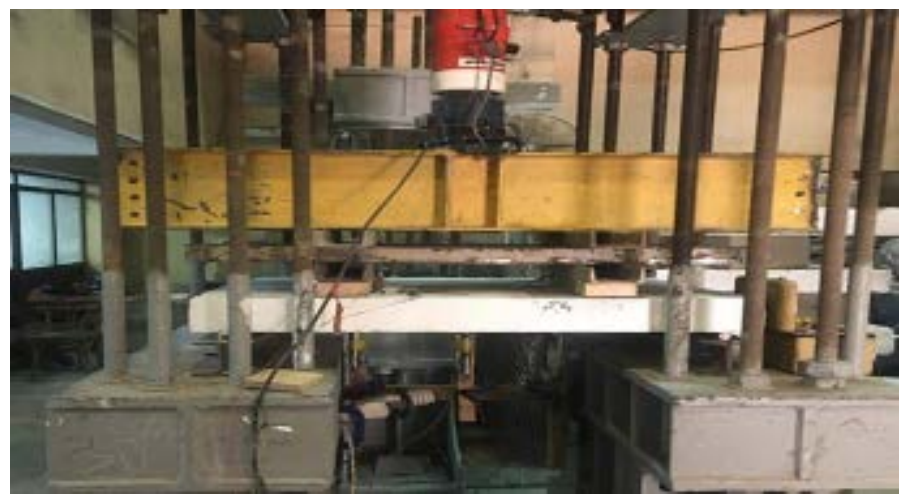

Figure 9: Two-line loads

The concrete compressive strength of concrete cubes of the tested specimens are shown in table1.

Table 1: Compressive strength of concrete cubes of the tested specimens at testing date

\begin{tabular}{|c|c|c|c|}
\hline Specimen & $\begin{array}{r}\text { Fcu (first } \\
\text { layer) }\end{array}$ & $\begin{array}{c}\text { Fcu } \\
\text { (second } \\
\text { layer) }\end{array}$ & Notes \\
\hline R-N-U & \multirow{3}{*}{\multicolumn{2}{|c|}{35.8}} & \multirow{3}{*}{$\begin{array}{c}\text { Normal strength concrete } \\
\text { Monolithic slab }\end{array}$} \\
\hline $\mathrm{R}-\mathrm{N}-\mathrm{O}$ & & & \\
\hline R-N-T & & & \\
\hline R-H-U & \multirow{3}{*}{\multicolumn{2}{|c|}{62}} & \multirow{3}{*}{$\begin{array}{l}\text { High strength concrete } \\
\text { Monolithic slab }\end{array}$} \\
\hline R-H-O & & & \\
\hline R-H-T & & & \\
\hline $0.1 \%-U$ & 36.8 & 61.7 & \multirow{8}{*}{ 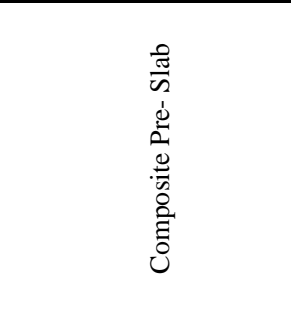 } \\
\hline $0.1 \%-\mathrm{O}$ & 36.2 & 60.2 & \\
\hline $0.1 \%-\mathrm{O}-\mathrm{R}$ & 36.4 & 60.8 & \\
\hline $0.1 \%-\mathrm{T}$ & 35.8 & 62 & \\
\hline $0.06 \%-U$ & 36.3 & 59.8 & \\
\hline $0.06 \%-\mathrm{O}$ & 35.5 & 59.5 & \\
\hline $\begin{array}{c}0.06 \%-\mathrm{O}- \\
\mathrm{R} \\
\end{array}$ & 36 & 60.8 & \\
\hline $0.06 \%-\mathrm{T}$ & 36 & 61 & \\
\hline
\end{tabular}

\section{TEST RESULTS AND DISCUSSION}

Discussion of test results concerning the experimental program of the tested monolithic and composite pre-slabs in terms of initiation and pattern of cracks, mode of failure and the relations between the applied loads and the measured deflections from zero load stage till failure, shear transfer, strain in shear connectors. 


\subsection{Pattern of cracks and mode of failure}

The initiation and pattern of cracks of the tested slabs can be clarify as follows:

\subsubsection{Monolithic slab $(R-N-U)$}

This slab was a monolithic slab with normal compressive strength subjected to uniformly distributed loads, the first crack was observed at load of 12 ton $\left(15 \mathrm{t} / \mathrm{m}^{2}\right)$ on the bottom surface at the section of maximum moment, nearly to the middle of the span. After this load level, another bottom cracks appeared as the increasing of load. From figure $\mathbf{1 0}$ it can be noticed that the bottom cracks were symmetrically about the axe passing through the mid-span of the slab.

The skew shear crack started to appear at load 29 ton (36.25 $\mathrm{t} / \mathrm{m}^{2}$ ), it was near the support from the two sides. Increasing the load after the skew shear crack appeared led to increase in the skew shear crack width and beginning of new shear cracks between the two main skew shear cracks till the specimen had a complete shear failure as shown in figure 11

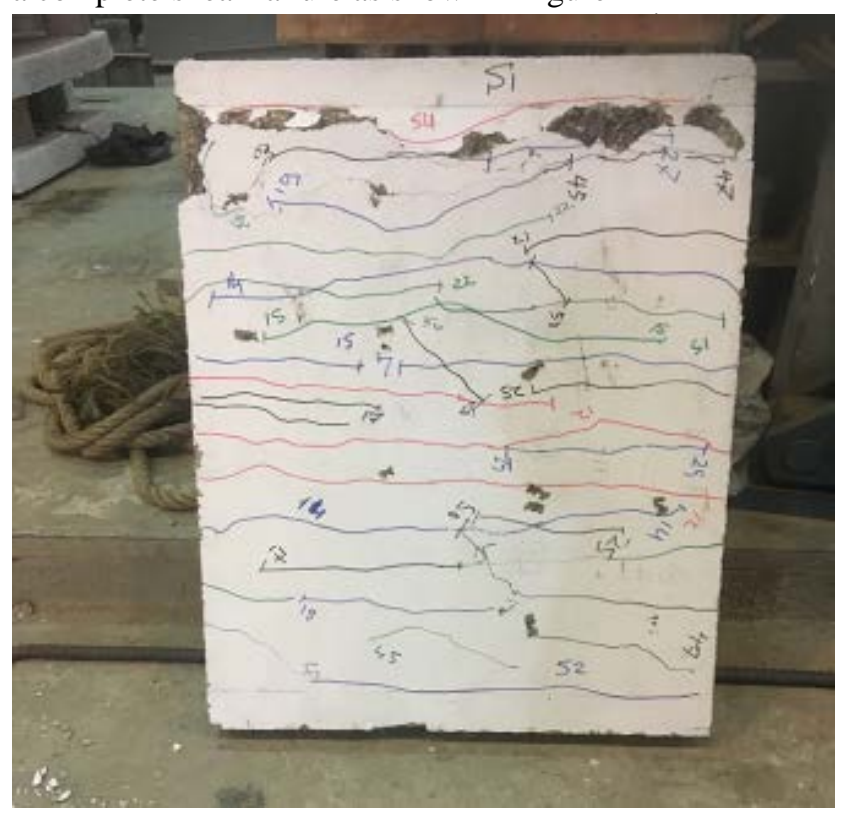

Figure 10: Cracks pattern of specimen (R-N-U)

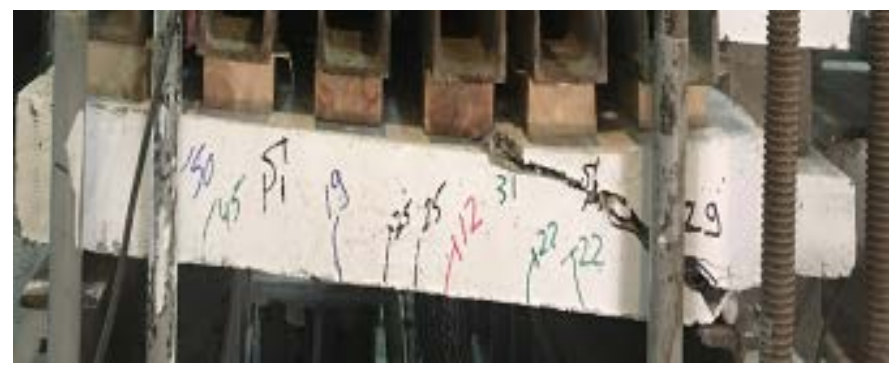

Figure 11: Shear failure of specimen (R-N-U)

\subsubsection{Monolithic slab $(R-H-U)$}

This slab was high strength concrete monolithic slab and subjected to uniformly distributed loads, the first crack was observed at load of 18 ton $\left(10 \mathrm{t} / \mathrm{m}^{2}\right)$ on the bottom surface at the section of maximum moment, nearly to the middle of the span. After this load level, another bottom cracks appeared as the increasing of load. From figure 4.4 it can be noticed that the bottom cracks were symmetrically about the axe passing through the mid-span of the slab. The skew shear crack started to appear at load 35 ton $\left(43.75 \mathrm{t} / \mathrm{m}^{2}\right)$, it was near the support from the two sides. Increasing the load after the skew shear crack appeared led to increase in the skew shear crack width and beginning of new shear cracks between the two main skew shear cracks till the specimen had a complete shear failure as shown in figure 12.

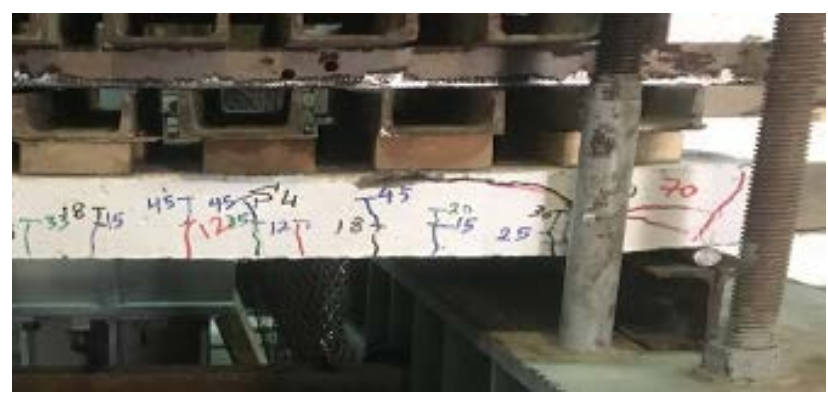

Figure 12: Shear cracks of specimen (R-H-U)

\subsubsection{Monolithic slab (R-N-O)}

This slab was a monolithic slab with normal compressive strength subjected to one-line load, the first crack was observed at load of 7.5 ton $(9.375 \mathrm{t} / \mathrm{m}$ line load) on the bottom surface at the section of maximum moment, nearly to the location of applied line load. After this load level, another bottom cracks appeared adjacent to the applied line load as the increasing of load. The skew shear crack started to appear at load 15 ton (18.75 t/m line load), it was near the support under the applied line load, increasing the load after the skew shear crack appeared led to increase in the skew shear crack width and beginning of new small skew shear cracks as shown in figure 13.

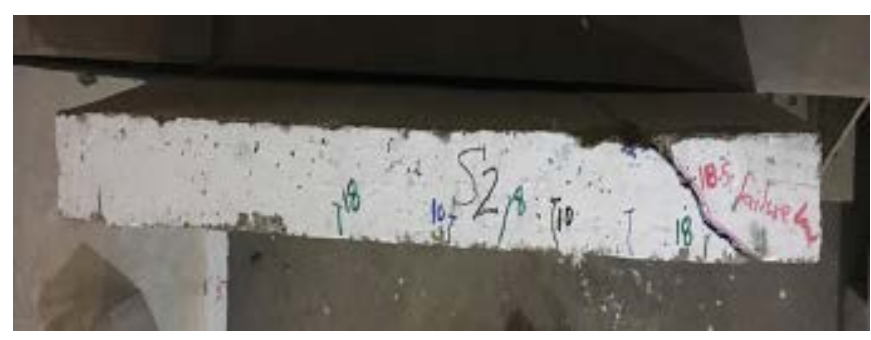

Figure 13: Shear cracks of specimen (R-N-O)

\subsubsection{Monolithic slab $(\mathrm{R}-\mathrm{H}-\mathrm{O})$}

This slab was high strength concrete monolithic slab and subjected to one-line load, the first crack was observed at load of 12.5 ton (15.625 t/m line load) on the bottom surface at the section of maximum moment, nearly to the location of applied line load. After this load level, another bottom cracks appeared adjacent to the applied line load as the increasing of load. The skew shear crack started to appear at load 21.5 ton $(26.875 \mathrm{t} / \mathrm{m}$ line load), it was near the support under the applied line load, increasing the load after the skew shear crack appeared led to increase in the skew shear crack width and beginning of new small skew shear cracks as shown in figure 14 .

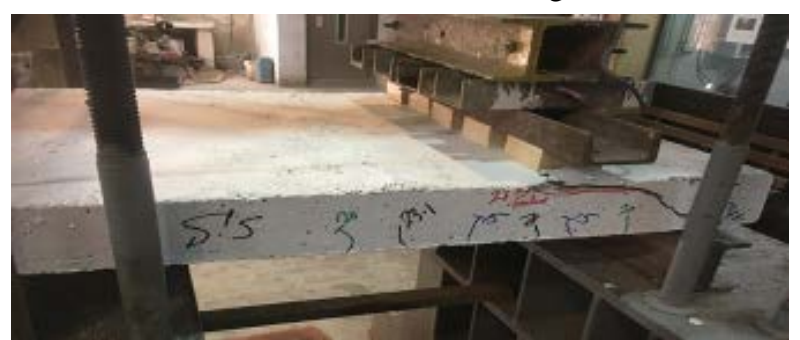

Figure 14: Shear cracks of specimen (R-H-O) 


\subsubsection{Monolithic slab $(R-N-T)$}

This slab was a monolithic slab with normal compressive strength subjected to uniformly distributed loads, the first crack was observed at load of 10 ton $(6.25 \mathrm{t} / \mathrm{m}$ for each line load) on the bottom surface at the section of maximum moment, nearly to the middle of the span. After this load level, another bottom cracks appeared on the both sides from the first crack as the increasing of load.

The skew shear crack started to appear at load 25 ton (15.63 $\mathrm{t} / \mathrm{m}$ for each line load), it was near the support under the applied line loads. Increasing the load after the skew shear crack appeared led to increase in the skew shear crack width and beginning of new small skew shear cracks till the specimen had a complete shear failure as shown in figure 15.

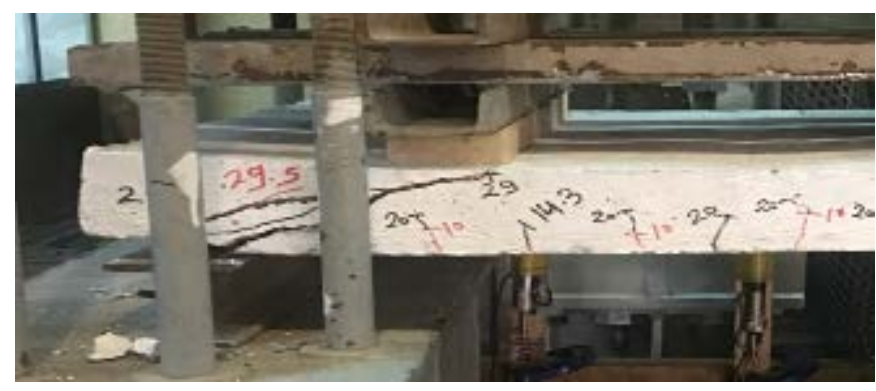

Figure 15: Shear cracks of specimen (R-N-T)

\subsubsection{Monolithic Slab $(R-H-T)$}

This slab was high strength concrete monolithic slab subjected to uniformly distributed loads, the first crack was observed at load of 15 ton (9.375 t/m for each line load) on the bottom surface at the section of maximum moment, nearly to the middle of the span. After this load level, another bottom cracks appeared on the both sides from the first crack as the increasing of load.The skew shear crack started to appear at load 36 ton $(22.5 \mathrm{t} / \mathrm{m}$ for each line load), it was near the support under the applied line loads. Increasing the load after the skew shear crack appeared led to increase in the skew shear crack width and beginning of new small skew shear cracks till the specimen had a complete shear failure as shown in figure 16.

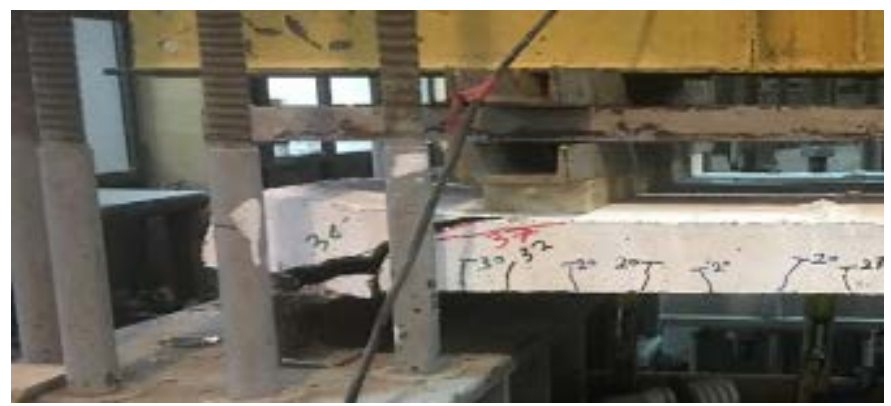

Figure 16: Shear cracks of specimen (R-H-T)

\subsubsection{Composite Slab (0.06\%- $U)$}

This slab was composite (normal strength at bottom -high strength concrete at the top) slab and subjected to uniformly distributed loads with uniform dowels distribution of ratio equals to $0.06 \%$ and the dowel length equals to $20 \phi$.The first crack was observed at load of 12.5 ton $\left(15.625 \mathrm{t} / \mathrm{m}^{2}\right)$ on the bottom surface at the section of maximum moment nearly to the midsection of the span. After this load level, another bottom cracks appeared as the of incrementing load.

The skew shear crack stared to appear at load of 30 ton (37.5 $\left.\mathrm{t} / \mathrm{m}^{2}\right)$, it was near the support. Increasing the load after the skew shear crack appeared led to increase in the skew shear crack width and creation of new shear cracks between the two main skew shear cracks till the specimen had complete shear failure at load of 52 ton $\left(65 \mathrm{t} / \mathrm{m}^{2}\right)$ as shown in figure $\mathbf{1 7}$.

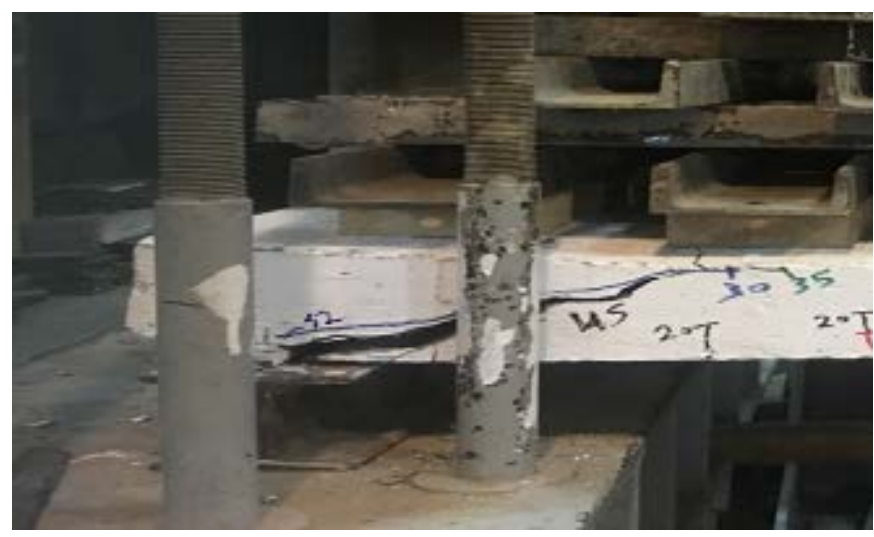

Figure 17: Shear cracks of specimen $(0.06 \%-\mathrm{U})$

\subsubsection{Composite Slab $(0.1 \%$ - $U)$}

This slab was composite (normal strength at bottom -high strength concrete at the top) slab and subjected to uniformly distributed loads with uniform dowels distribution of ratio equals to $0.1 \%$ and the dowel length equals to $20 \phi$.The first crack was observed at load of 15 ton $\left(18.75 \mathrm{t} / \mathrm{m}^{2}\right)$ on the bottom surface at the section of maximum moment nearly to the midsection of the span. After this load level, another bottom cracks appeared as the increasing of load. The skew shear crack stared to appear at load of 50 ton $\left(62.5 \mathrm{t} / \mathrm{m}^{2}\right)$, it was near the support. Increasing the load after the skew shear crack appeared led to increase in the skew shear crack width and creation of new shear cracks between the two main skew shear cracks till the specimen had complete shear failure at load of 64 ton as shown in figure 18.

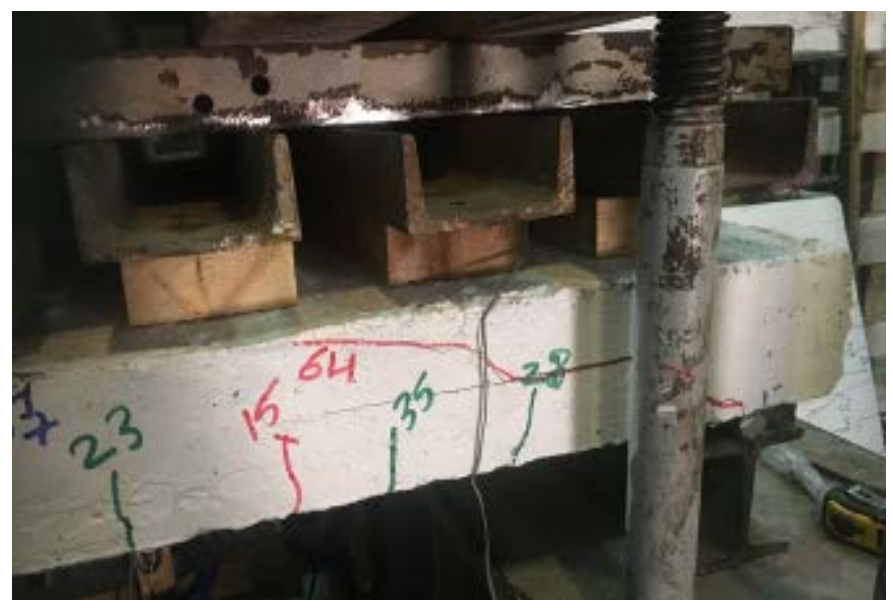

Figure 18: Shear cracks of specimen $(0.1 \%-\mathrm{U}$

\subsubsection{Composite Slab (0.06\%- O)}

This slab was composite (normal strength at bottom -high strength concrete at the top) slab and subjected to uniformly one-line load with uniform dowels distribution of ratio equals to $0.06 \%$ and the dowel length equals to $20 \phi$.The first crack was observed at load of 7 ton $(8.75 \mathrm{t} / \mathrm{m}$ line load $)$ on the 
bottom surface at the section of maximum moment nearly to the location of applied line load. After this load level, another bottom cracks appeared adjacent to the applied line load as the increasing of load.

The skew shear crack stared to appear at load of 18 ton $(22.5 \mathrm{t} / \mathrm{m}$ line load), it was near the support under the applied line load. Increasing the load after the skew shear crack appeared led to increase in the skew shear crack width and creation of new shear cracks between the two main skew shear cracks till the specimen had complete shear failure at load of 19.5 ton (24.375 t/m line load) as shown in figure 19.

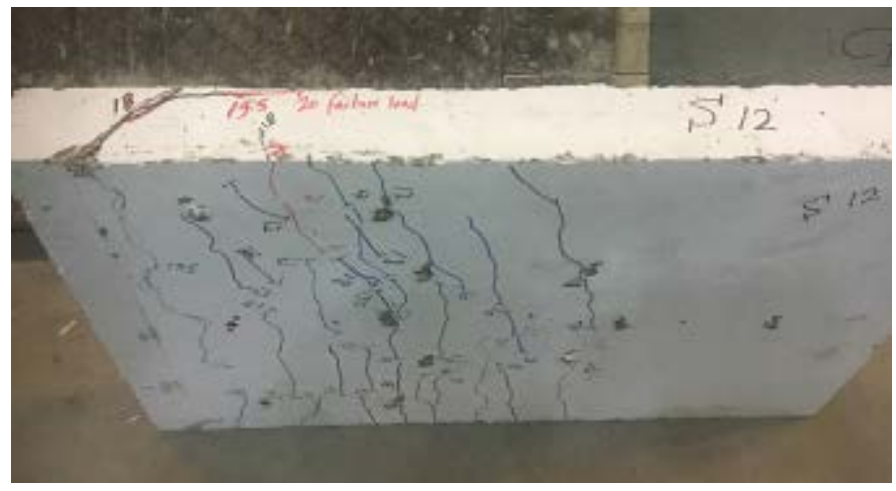

Figure 19: Shear cracks of specimen $(0.06 \%-\mathrm{O})$

\subsubsection{Composite Slab (0.06\%-O-R)}

This slab was composite (normal strength at bottom-high strength concrete at the top) slab and subjected to uniformly one-line load with uniform dowels distribution of ratio equals to $0.06 \%$, the dowel length equals to $20 \phi$ and had roughening on the interface area between the two concrete layers. The first crack was observed at load of 7.5 ton $(9.375 \mathrm{t} / \mathrm{m}$ line load) on the bottom surface at the section of maximum moment nearly to the location of applied line load. After this load level, another bottom cracks appeared adjacent to the applied line load as the increasing of load.

The skew shear crack stared to appear at load of 19 ton (23.75 $\mathrm{t} / \mathrm{m}$ line load), it was near the support under the applied line load. Increasing the load after the skew shear crack appeared led to increase in the skew shear crack width and creation of new shear cracks between the two main skew shear cracks till the specimen had complete shear failure at load of 22 ton (27.5t/m line load) as shown in figure 4.20.

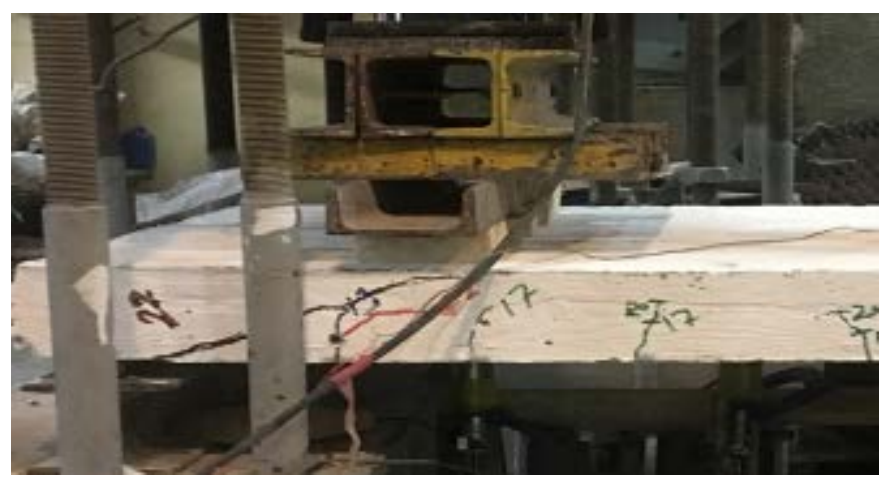

Figure 20: Shear cracks of specimen (0.06\%-O-R)

\subsubsection{Composite Slab (0.1\%- O)}

This slab was composite (normal strength at bottom -high strength concrete at the top) slab and subjected to uniformly one-line load with uniform dowels distribution of ratio equals to $0.1 \%$ and the dowel length equals to $20 \phi$.The first crack was observed at load of 7 ton $(8.75 \mathrm{t} / \mathrm{m}$ line load) on the bottom surface at the section of maximum moment nearly to the location of applied line load. After this load level, another bottom cracks appeared adjacent to the applied line load as the increasing of load. The skew shear crack stared to appear at load of 19 ton (23.75t/m line load), it was near the support under the applied line load. Increasing the load after the skew shear crack appeared led to increase in the skew shear crack width and creation of new shear cracks between the two main skew shear cracks till the specimen had complete shear failure at load of 23 ton (28.75 t/m line load) as shown in figure 21.

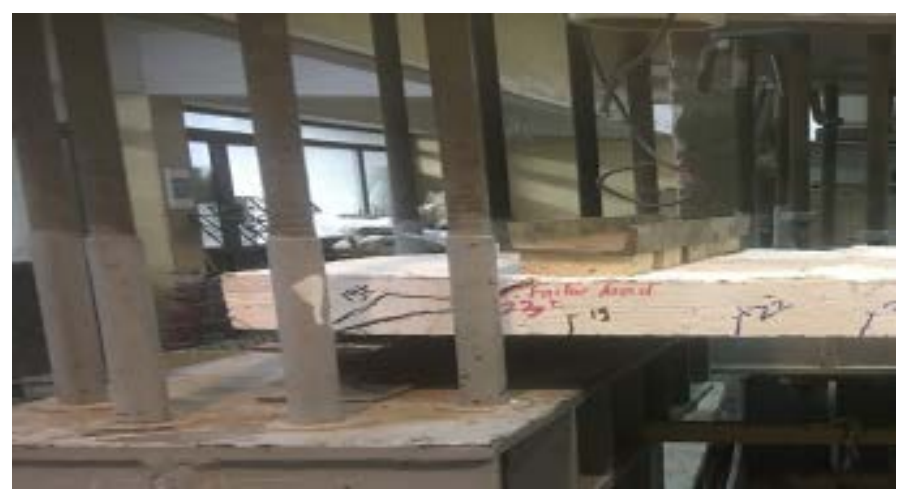

Figure 21: Shear cracks of specimen $(0.1 \%-\mathrm{O})$

\subsubsection{Composite Slab (0.1\%- O-R)}

This slab was composite (normal strength at bottom -high strength concrete at the top) slab and subjected to uniformly one-line load with uniform dowels distribution of ratio equals to $0.1 \%$, the dowel length equals to $20 \phi$ and had roughening on the interface area between the two concrete layers. The first crack was observed at load of 8.5 ton $(10.625 \mathrm{t} / \mathrm{m}$ line load) on the bottom surface at the section of maximum moment nearly to the location of applied line load.

After this load level, another bottom cracks appeared adjacent to the applied line load as the increasing of load. The skew shear crack stared to appear at load of 22 ton $(27.5 \mathrm{t} / \mathrm{m}$ line load), it was near the support under the applied line load. Increasing the load after the skew shear crack appeared led to increase in the skew shear crack width and creation of new shear cracks between the two main skew shear cracks till the specimen had complete shear failure at load of 25 ton (31.25 t/m line load) as shown in figure 22.

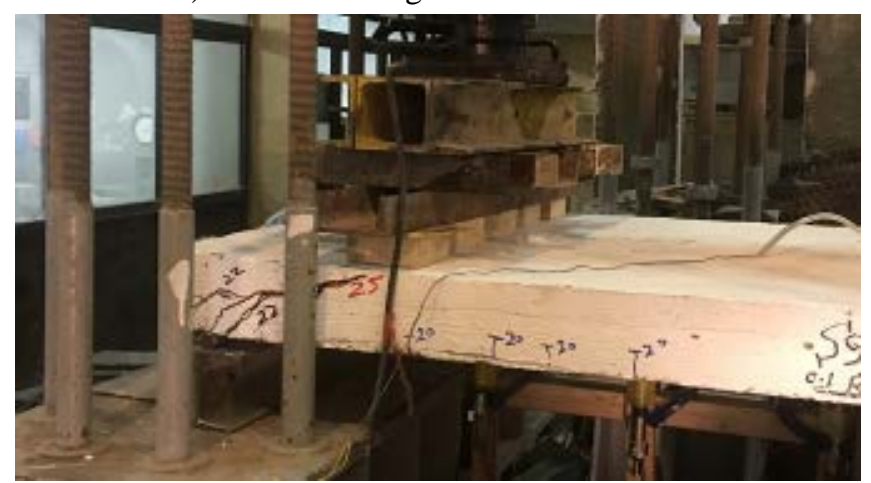

Figure 22: Shear cracks of specimen (0.1\%-O-R) 


\subsubsection{Composite Slab (0.06\%- T)}

This slab was composite (normal strength at bottom -high strength concrete at the top) slab and subjected to uniformly two-line loads with concentrated dowels distribution of ratio equals to $0.06 \%$ and the dowel length equals to $20 \phi$. The first crack was observed at load of 8 ton ( $5 \mathrm{t} / \mathrm{m}$ for each line load) on the bottom surface at the section of maximum moment nearly to the middle of the span. After this load level, another bottom cracks appeared on the both sides from the first crack as the increasing of load.

The skew shear crack stared to appear at load of 25 ton (15.62 $\mathrm{t} / \mathrm{m}$ for each line load), it was near the support under the applied line loads. Increasing the load after the skew shear crack appeared led to increase in the skew shear crack width and creation of new shear cracks between the two main skew shear cracks till the specimen had complete shear failure at load of 29 ton (18.125 t/m for each line load) as shown in figure 23.

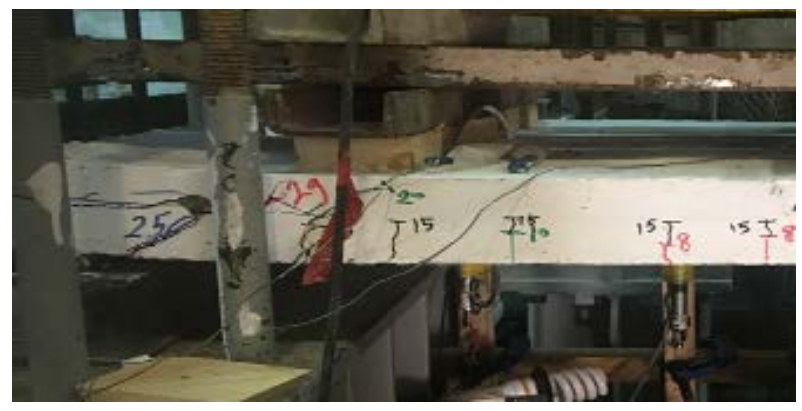

Figure 23: Shear cracks of specimen $(0.06 \%-\mathrm{T})$

\subsubsection{Composite Slab (0.1\%- T)}

This slab was composite (normal strength at bottom -high strength concrete at the top) slab and subjected to uniformly two-line loads with concentrated dowels distribution of ratio equals to $0.1 \%$ and the dowel length equals to $20 \phi$. The first crack was observed at load of 11.5 ton $(7.18 \mathrm{t} / \mathrm{m}$ for each line load) on the bottom surface at the section of maximum moment nearly to the middle of the span. After this load level, another bottom cracks appeared on the both sides from the first crack as the increasing of load. The skew shear crack stared to appear at load of 25 ton (17.31 t/m for each line load), it was near the support under the applied line loads. Increasing the load after the skew shear crack appeared led to increase in the skew shear crack width and creation of new shear cracks between the two main skew shear cracks till the specimen had complete shear failure at load of 34 ton $(21.25 \mathrm{t} / \mathrm{m}$ for each line load) as shown in figure 24.

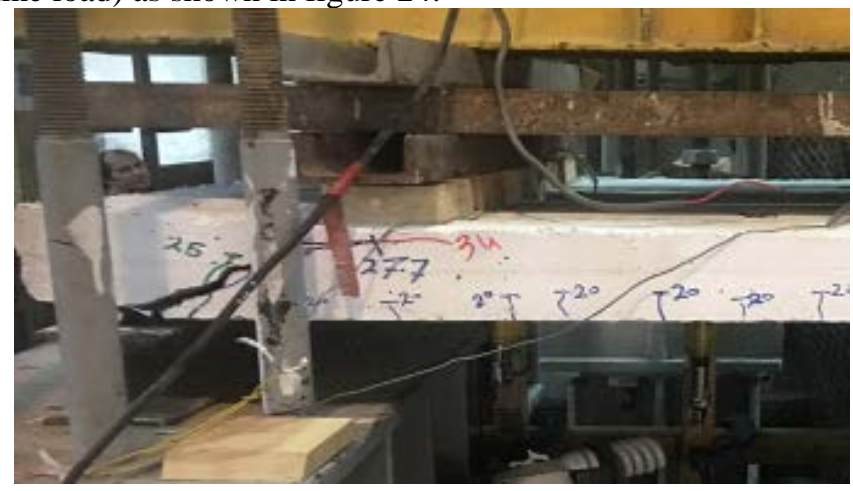

Figure 24: Shear cracks of specimen $(0.1 \%-\mathrm{T})$

\subsection{Cracking loads}

Table 2 shows the values of the cracking load for both monolithic and composite pre-slabs, the first cracking load occurred at the bottom surface of the specimens nearly at the section of maximum bending moment according to loading type. From fig table 2, for monolithic and composite slabs it can be noticed that the cracking load was as follow:

1- Using high strength concrete at the top layer and concentrated dowels distribution at the section of maximum bending moment lead to increase the cracking load of composite pre-slabs.

2- Increasing the percentage of shear connectors lead to increase the cracking load because of the improvement of the composite action.

3- Using rough surface between two concrete layers had no effect on cracking load for pre-slabs in (group 2,3) because of using uniform dowel distribution which had a small dowels area at the section of maximum moment.

Table 2: Results of tested specimens

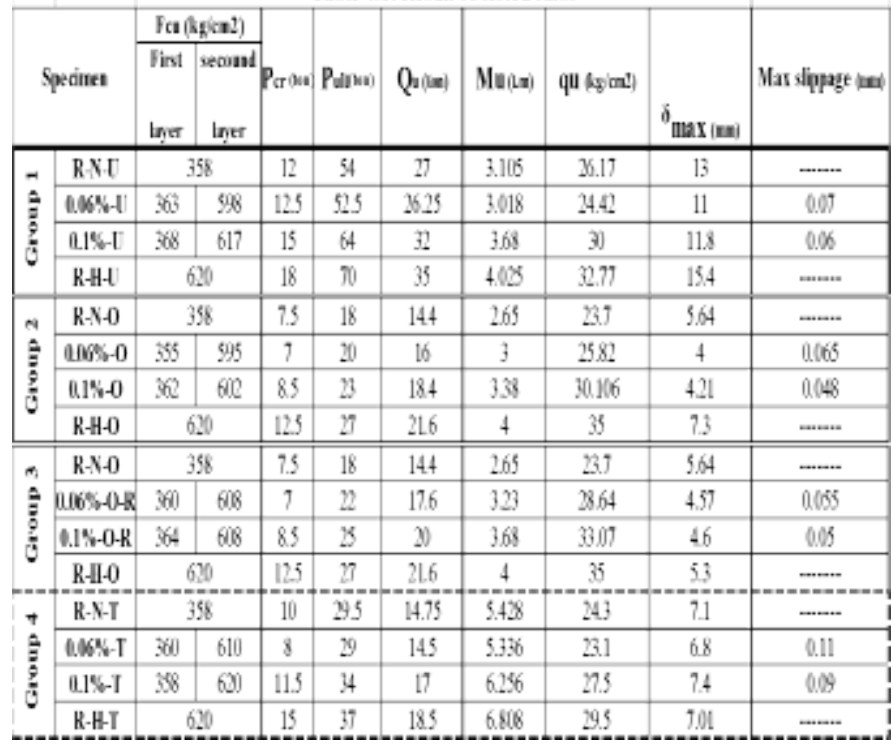

\subsection{Failure loads}

Referring to Figure 25, shows the failure loads for the tested monolithic and pre-slabs, it can be noticed that the failure load of composite pre-slab is linearly proportional as the shear connectors ratio increases.

For group 1 under uniformly distributed loads, the failure load of composite pre-slab $(0.06 \%-U)$ with shear connectors area equals to $0.06 \%$ from the interface area and uniform dowels distribution was about $97 \%$ of the corresponding monolithic slab (R-N-U), and about $75 \%$ of the monolithic slab (R-H-U), while the failure load for composite pre-slab $(0.1 \%-U)$ was about $118.5 \%$ of the corresponding monolithic slab R-N-U and $91.5 \%$ of the corresponding monolithic slab (R-H-U).

For group 2 under uniformly one-line loads, the failure load of composite pre-slab $(0.06 \%-\mathrm{O})$ was about $111.11 \%$ of the corresponding monolithic slab (R-N-O), while was $74 \%$ of the corresponding monolithic slab (R-H-O). The failure load of the composite pre-slab $(0.1 \%-\mathrm{O})$ was about $127.7 \%$ for the corresponding monolithic slab (R-N-O), while it was about $85 \%$ of the corresponding monolithic slab (R-H-O). 
For group 3 under uniformly one-line loads, the failure load of the composite pre-slab $(0.06 \%-\mathrm{O}-\mathrm{R})$ with the interface area (Rough) was about $122.2 \%$ for the corresponding monolithic slab (R-N-O), while the failure load was about $81.5 \%$ for the corresponding monolithic slab (R-H-O). The failure load of the composite pre-slab $(0.1 \%-\mathrm{O}-\mathrm{R})$ with the interface area (Rough) was about $138.8 \%$ for the corresponding monolithic slab (R-N-O), while it was about $92.5 \%$ of the corresponding monolithic slab (R-H-O).

For group 4 under uniformly two line loads, the failure load of composite pre-slab $(0.06 \%-\mathrm{T})$ with shear connectors area equals to $0.06 \%$ from the interface area and concentrated dowels distribution was about $98 \%$ of the corresponding monolithic slab (R-N-T), was about $78 \%$ for the corresponding monolithic slab (R-H-T), while the failure load of the composite pre-slab (0.1\%-T) for the corresponding monolithic slab (R-N-T) was about $115.25 \%$ and also the failure load for composite pre-slab $(0.1 \%-\mathrm{T})$ about $92 \%$ of the corresponding monolithic slab (R-H-T).

from these results it we can noticed that the concentration distribution of shear dowels according to the shear force distribution, with the interface area rough and using high strength concrete in the top layer led to increase in the ultimate capacity of the specimen which mean increasing in the composite action between the two concrete layers of the preslabs.

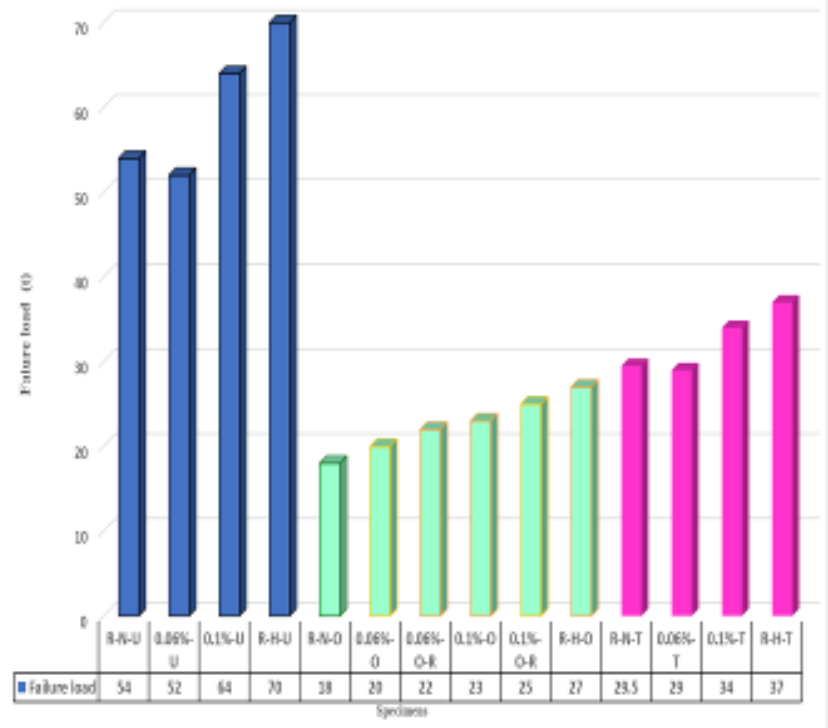

Figure 25: Failure loads of tested specimens

\section{4 load-deflection curves}

The deflection of the tested monolithic and composite slabs was measured at $0.2 \mathrm{~L}, 0.5 \mathrm{~L}$ and $0.8 \mathrm{~L}$ and the maximum deflection plotted against the applied load from zero loading up to failure as shown in figure 26 through figure 29. It can be noticed that the relation between the load and the deflection was approximately linear up to cracking load then it was nonlinear distribution due to excessive cracking in the concrete.

1-Figure 26 shows load deflection curves for group 1, which study influence of changing percentage of shear dowels on deflection in case of uniform distribution load. It could be noticed that, for all specimens the more the percentage of shear dowels the less the mid span deflection. In addition, it could also be noticed that specimen $(0.1 \%-\mathrm{U})$ showed a stiffer behavior than the reference specimen (R-N-U) which means that pre-slab $(0.1 \%-U)$ had an increase in the maximum deflection about $43 \%$ of that of the monolithic(R-N-U), also the other specimen $(0.06 \%-U)$ showed less stiffness compared to reference specimen (R-N-U). This could be attributed to that percentage of shear dowels $0.1 \%$ are sufficient to increase in the ultimate capacity of the section which behave as if the specimen was casted as one layer.

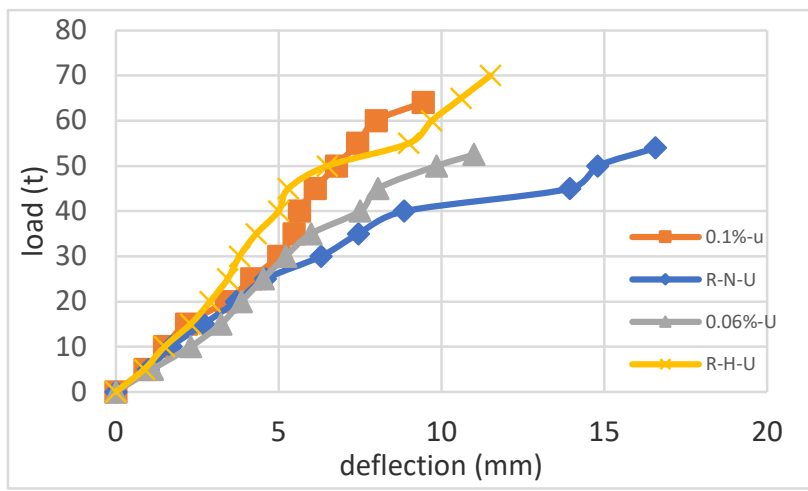

Figure 26: Vertical deflection at mid span (group 1)

2. Figure 27 shows load deflection curves for group 2, which study influence of changing percentage of shear dowels and condition of the interface area between the two layers as casted surface on deflection in case of one-line load. When comparing the load deflection curves of the composite specimens $(0.1 \%-\mathrm{O}$, $0.06 \%-\mathrm{O}$ ) and monolithic specimens (R-N-O and R-H-O), it can be noticed that composite slabs $(0.1 \%-\mathrm{O}, 0.06 \%-\mathrm{O})$ had an increase in the maximum deflection by about $42 \%$ and $14.5 \%$ respectively of that of the monolithic slab (R-N-O). On the other hand, when the monolithic slab (R-H-O) compared to these pre-slabs it can be noticed that, it had an increase in the maximum deflection by about $22 \%$ and $47 \%$ of that of the composite pre-slabs $(0.1 \%-\mathrm{O}, 0.06 \%-\mathrm{O})$ respectively.

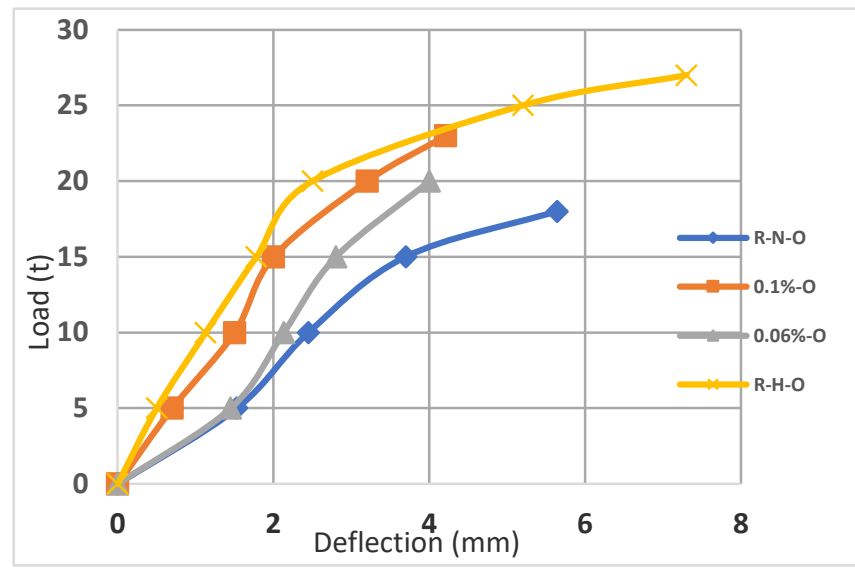

Figure 27: Vertical deflection at 0.2L (group 2)

Also, Figure 28 shows the results of specimens in group 3 (0.1\%-O-R) and (0.06\%-O-R) it can be noticed that, they had an increase in the maximum deflection by about $47 \%$ and $33 \%$ respectively of that of the monolithic slab (R-N-O). On the other hand, when these pre-slabs compared to monolithic slab 
(R-H-O) it can be noticed that it had an increase in the maximum deflection by about $14 \%$ and $32 \%$ respectively of that of the both composite pre-slabs $(0.1 \%-\mathrm{O}-\mathrm{R})$ and $(0.06 \%-\mathrm{O}-$ R). Figure 29 shows load deflection curves for group 4, which study influence of changing percentage of shear dowels and their concentration on deflection in case of uniformly two-line loads. For the load-deflection curve of the pre-slabs $(0.1 \%-\mathrm{T}$, $0.06 \%-\mathrm{T}$ ) and the monolithic slabs (R-N-T, R-H-T), it can be noticed that the pre-slab the pre-slab $(0.06 \%-\mathrm{T})$ had approximately the same deflection curve of the monolithic slab (R-N-T). While the other pre-slab $(0.1 \%$-T) had an increase in the maximum deflection by about $20 \%$ of that of the monolithic slab (R-N-T). Also, it had a maximum deflection less about $41 \%$ than the maximum deflection of the monolithic slab (R-HT).

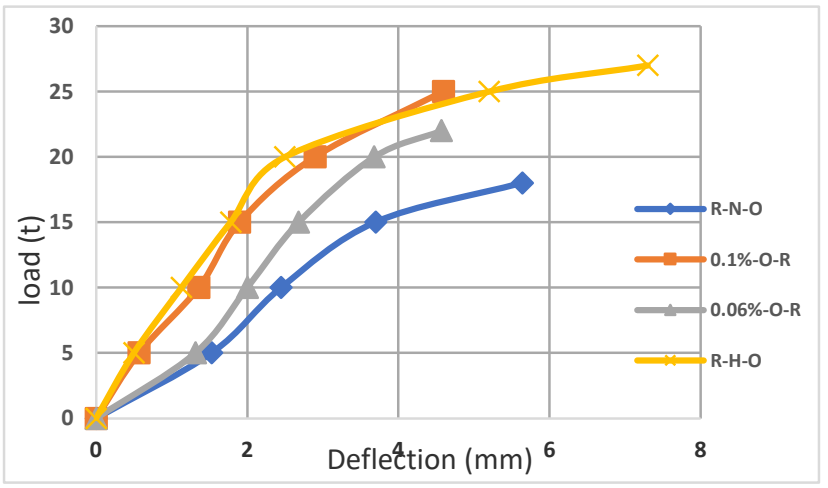

Figure 28: Vertical deflection at 0.2L (group 3)

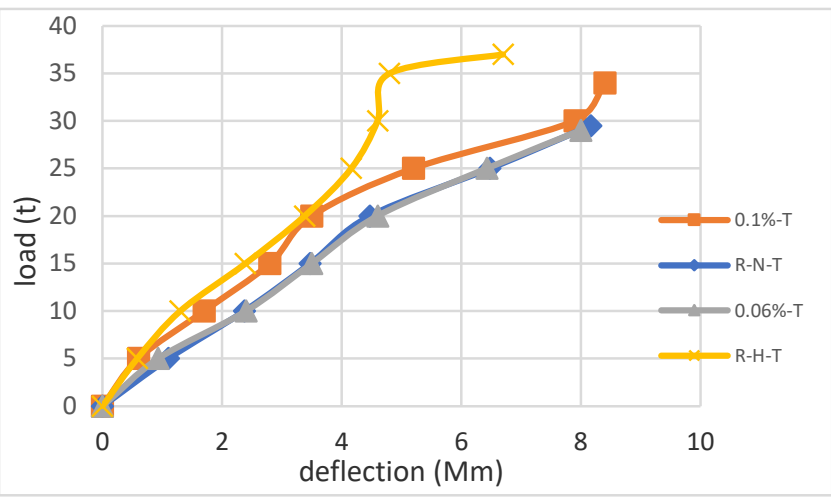

Figure 29: Vertical deflection at 0.2L (group 4)

\subsection{Shear transfer along the interface}

Table 2 and Figure 34 shows the shear strength qu values which were calculated at the failure load for both monolithic and pre-slabs. it can be noticed that

1. Increasing of shear connectors ratio led to increase in the shear strength as in case of pre-slabs $0.1 \%$-U was about $114.6 \%, 0.1 \%-\mathrm{O}$ was about $127 \%, 0.1 \%-\mathrm{O}-\mathrm{R}$ was about 139.5 and $0.1 \%$ - $\mathrm{T}$ was about $113 \%$ ) when compared to the corresponding monolithic (normal concrete strength) specimen which each specimen belongs to.
2. The change in case of loading from uniformly distributed to concentrated line load for both specimens (0.06\%-U, $0.06 \%-O)$ had a very small effect in the shear strength but when $0.1 \%$ had been used there were a slight increase in the shear strength, in both specimens $(0.06 \%-\mathrm{O}-\mathrm{R}$ and $0.1 \%-\mathrm{O}-\mathrm{R}$ ) there where a significant increase in the shear strength was about $85 \%$ and $92 \%$ respectively.

3. From group1 it can be noticed that pre-slabs under uniformly distributed loads and with uniform distribution of shear dowels led to increase in the shear strength of the composite pre-slab $0.1 \%-\mathrm{U}$ which had been reached the shear strength of the corresponding monolithic slab R-N-T was about $13 \%$.

4. For (group 2\&3) using Roughness in composite pre-slabs (0.06\%-O-R ,0.1\%-O-R) at the interface area between the two layers (normal and high strength concrete) led to increase the shear transfer strength compared with the composite pre-slabs $(0.06 \%-\mathrm{O}, 0.1 \%-\mathrm{O})$ was about $10 \%$.

5. From result of group 4 under uniformly two-line loads, it can be noticed that concentration of shear dowels led to increase in the shear strength of the composite pre-slab $0.1 \%$ - $\mathrm{T}$ which had been reached the shear strength of the corresponding monolithic slab R-N-T was about $12 \%$.

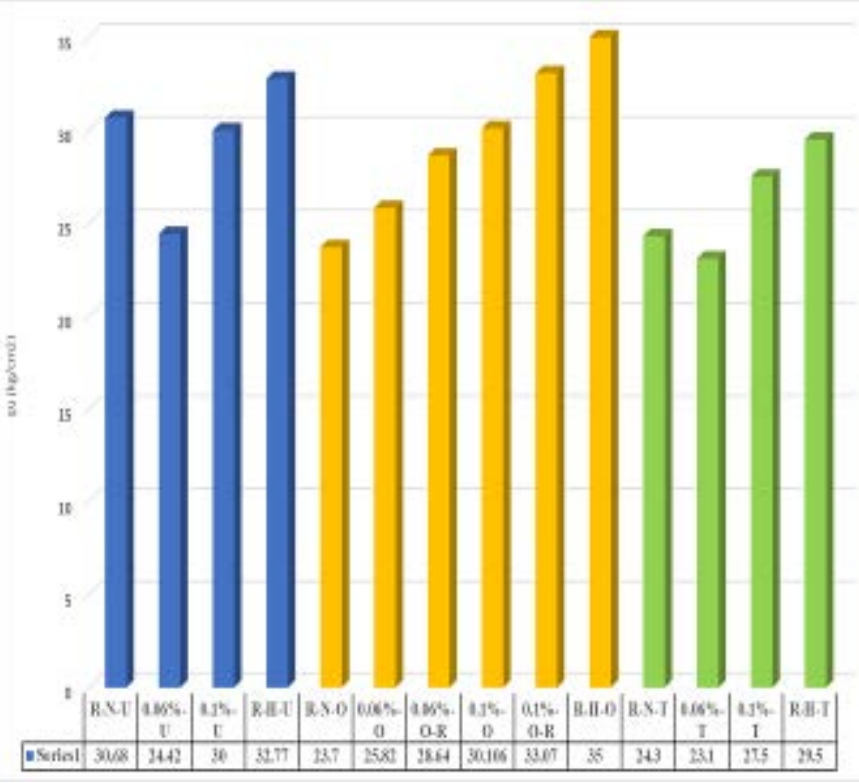

Figure 34: Ultimate shear strength at interface of the tested pre-slabs

\subsubsection{Strain in shear connectors}

the maximum strain in the shear connectors plotted against load as shown in figure 39 through figure 43, it is clear that:

a- The increase in shear connectors ratio of the dowels led to decrease in the dowel's strain because of the large dowel's cross-sectional area at the location of the maximum shear stress along the interface.

b- Using roughness in both pre-slabs $(0.1 \%-\mathrm{R})$ and $(0.06 \%-\mathrm{R})$ lead to decrease in the dowel's strain because of increasing the ultimate shear transfer strength and decrease both slip and crack width at all level of loading. 


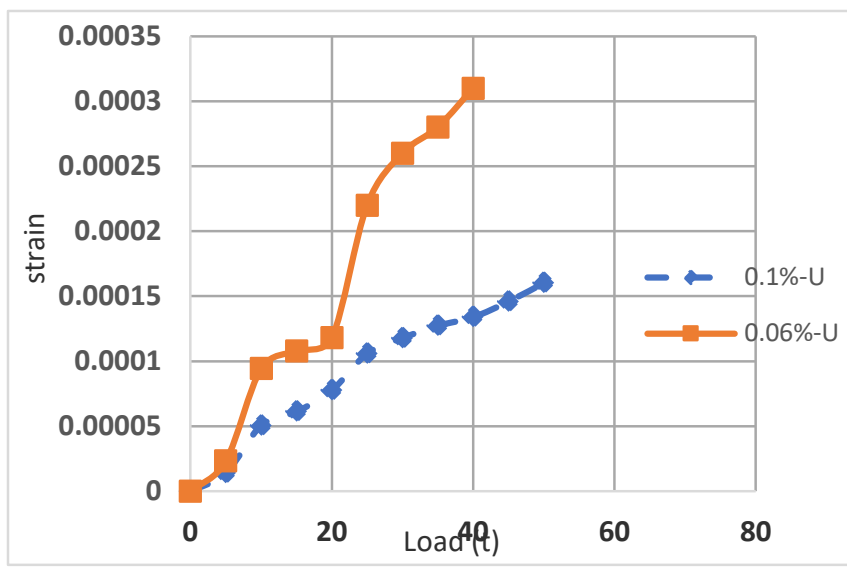

Figure 39: Maximum strain in dowels (group 1)

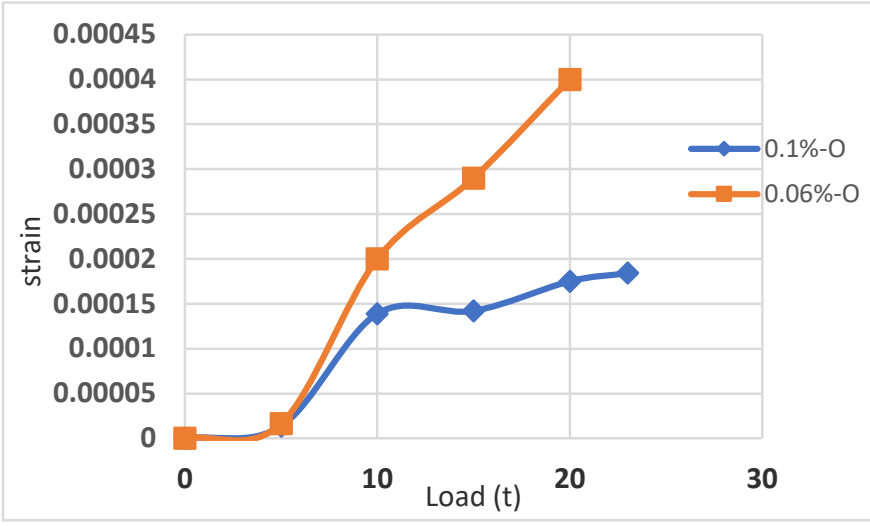

Figure 40: Maximum strain in dowels (group 2)

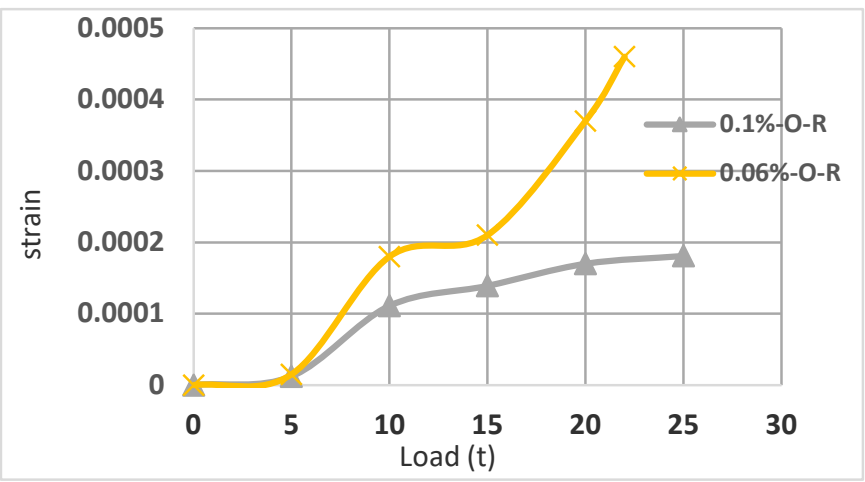

Figure 41: Maximum strain in dowels (group 3)

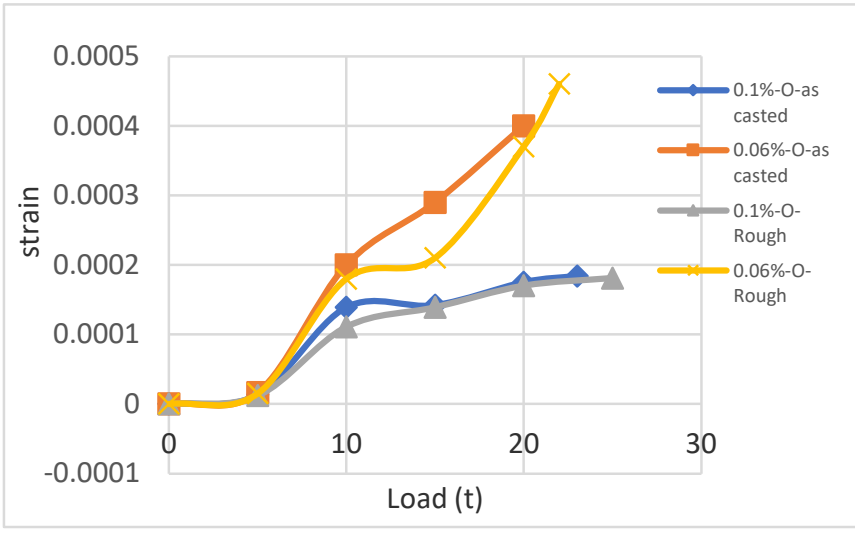

Figure 42: Maximum strain in dowels (group 2\& 3)

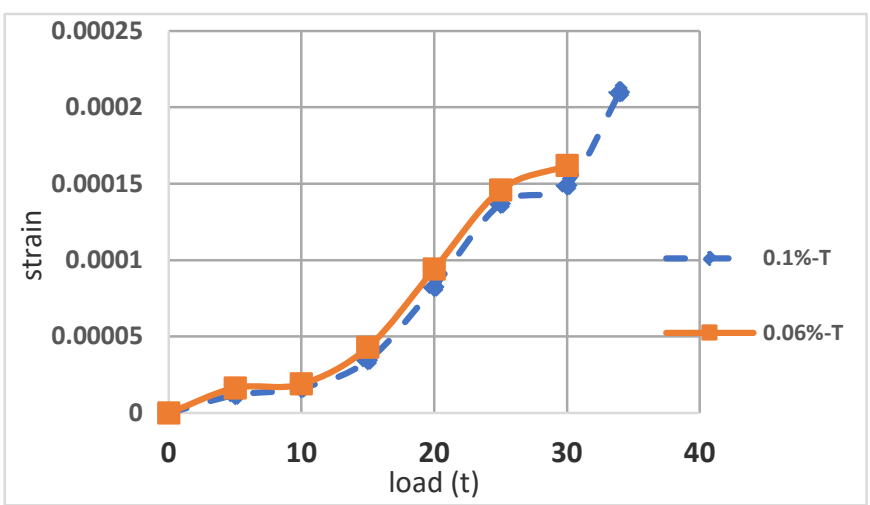

Figure 43: Maximum strain in dowels (group 4)

\subsection{8 slippage}

The horizontal slippage of the tested pre-slabs was measured and plotted against the applied loads as shown in figure 44 through figure 47, it can be noticed that increasing shear dowels percentages in all pre-slabs to $0.1 \%$ led to a decrease in horizontal slippage comparing with the pre-slab with shear dowels percentage equals to $0.06 \%$; also, the horizontal slippage happened slightly before reaching the ultimate load. It can be also noticed that that maximum slippage equals to 0.11 $\mathrm{mm}$ occurred for specimen $(0.06 \%$ - $\mathrm{T})$ which was tested under the effect of two-line loads.

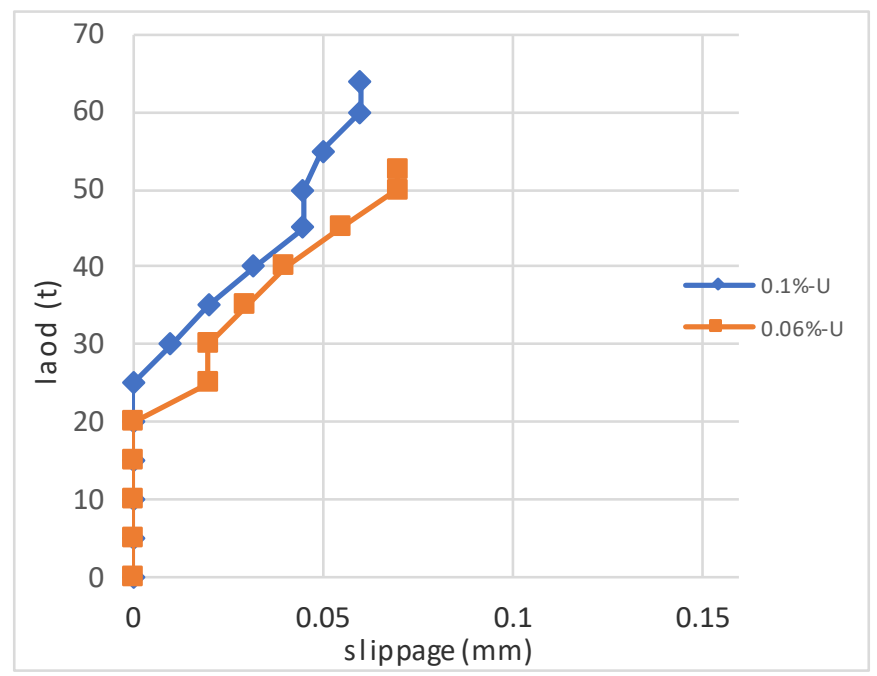

Figure 44: Slippage of tested pre-slabs (group 1)

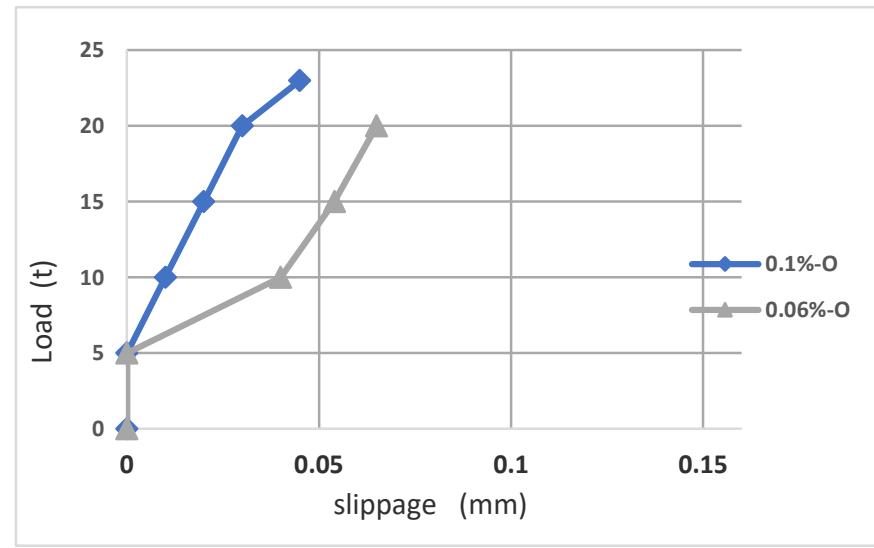

Figure 45: Slippage of tested pre-slabs (group 2) 


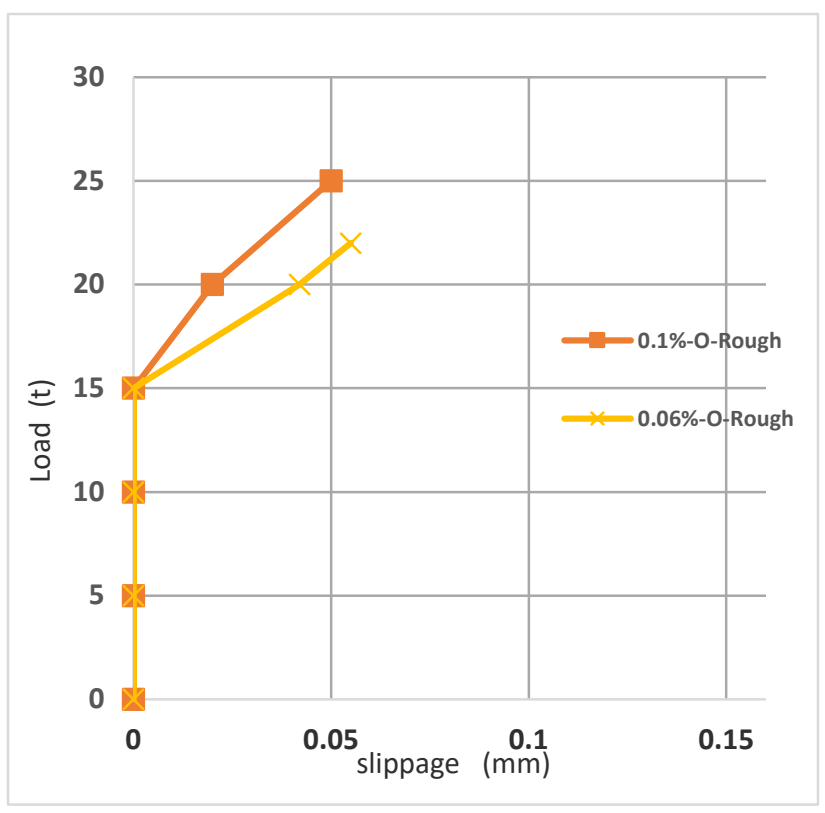

Figure 46: Slippage of tested pre-slabs (group 3)

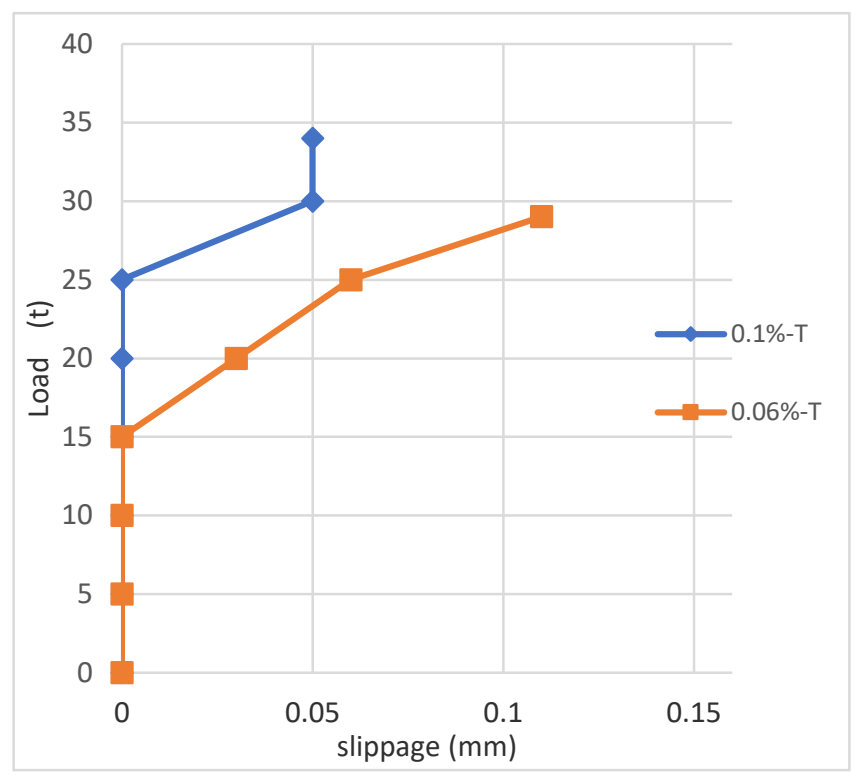

Figure 47: Slippage of tested pre-slabs (group 4)

\section{CONCLUSIONS}

1- The tested slabs had been succeeded to change the failure mode from flexure to shear.

2- Increasing of shear connectors ratio from $0.06 \%$ to $0.1 \%$ in the tested pre-slabs with uniform dowels distribution led to:

(a)- Increasing in ultimate load and shear strength with about $82 \%$ and $81 \%$, respectively for pre-slabs tested under uniform distributed load.

(b)- Increasing in ultimate load and shear strength with about $87 \%$ and $86 \%$, respectively for pre-slabs tested under oneline load. (c)- Decrease in the horizontal slippage by about $85 \%$ in case of tested specimens under the effect of uniformly distributed loads and about $74 \%$, in case of tested specimens under the effect of one-line load (as casted) and approximately the same slippage in case of roughening the interface surface, also about $81 \%$ in case of tested specimens under the effect of two-line load.

(d)- Increasing in ductility for pre-slabs tested under uniform distributed load, one-line load and two-line load which has been noticed in high deformation before failure.

(e)- Increase shear dowels ratio led to decrease in dowels' strain because of large dowels' cross-sectional area at the location of maximum shear stress along the interface area between two layers.

3- Increasing of shear connectors ratio from $0.06 \%$ to $0.1 \%$ in the tested pre-slabs with concentrated dowels distribution led to increase ultimate load and shear strength with about $85 \%$ and $84 \%$, respectively for preslabs tested under two-line load.

4- Increase of the interface roughening between the upper and lower slab led to increase the shear strength for preslab [(0.06\%-O-R), (0.1\%-O-R)] about $(17 \%, 28 \%)$, respectively over the shear strength of the monolithic specimen (R-N-O), also less than the monolithic specimen (R-H-O) about (18\%, 5\%)].

\section{REFERENCES}

[1] El-Behairy, Sh., and Abu El-Enin, A.W., "Behavior of Simply Supported Pre-Slab System”, Bulletin No. 15-C20, Faculty of Engineering, Ain Shams Univ., 1984.

[2] Zaky, W. and Rabie, M., "Effect of Cases of Loading and Distribution of Shear Connectors on the Behavior of One -Way Composite PreSlabs”, Life Science Journal, Vol. 9, No. 2, pp. 435-443, 2012

[3] Rabie, M., "Shear Transfer in Composite Reinforced Concrete Sections”, Ph.D. Thesis. Faculty of Engineering. Cairo Univ., 1994.

[4] Abou El-Maaty, M.A., "Composite Corrugated Pre-Cast Reinforced Concrete Deck Slabs”, Ph.D. Thesis. Faculty of Engineering. Cairo Univ., 1997.

[5] El-Zanaty, A., "Shear Transfer Behavior of Initially Cracked Concrete with Compressive Stresses Normal to the Shear Plane”, Egyptian society of Engineers, Vol. 34, No. 1, 1995.

[6] Hussien, I.A., "Effect of Shear Connectors on Composite Concrete Beams”, M.Sc. Thesis. Faculty of Eng. Cairo Univ., 1991.

[7] Abdel-Hay, A.SH., "Effect of Interface Position and Percentage of Shear Connectors on the Behavior of One-Way Composite Pre-Slabs", Journal of American Science; Vol. 8, No.9, pp. 325-332, 2 